\title{
Open Innovation in the Public Sector: A Dynamic Capabilities Perspective and the Role of Information Technology
}

\author{
Thibaut Coulon \\ ESG-UQAM \\ coulon.thibaut@uqam.ca
}

\author{
Mathieu Templier \\ Université Laval \\ mathieu.templier@fsa.ulaval.ca
}

\author{
Simon Bourdeau \\ ESG-UQAM \\ bourdeau.s@uqam.ca
}

\author{
Amandine Pascal \\ Université Aix-Marseille \\ amandine.pascal@univ-amu.fr
}

\author{
Dragos Vieru \\ TÉLUQ University \\ dragos.vieru@uqam.ca
}

\begin{abstract}
Public sector organizations (PSOs) are facing important structural, financial, environmental, and technological pressures. To adapt and respond to this complex and changing environment, PSOs need to deploy new innovative and collaborative approaches to capture and capitalize on specialized knowledge coming from a wider number of contributors. Open innovation (OI) is one such promising approach. Drawing on a dynamic capabilities perspective and based on an analysis of 100 case study reports of OI initiatives, we identified 16 key organizational actions deployed by PSOs to implement OI initiatives. Data analysis showed that PSOs' dynamic capabilities of sensing, seizing and transforming are enacted and collectively used to engage in OI initiatives through these 16 organizational actions. In virtually all of these organizational actions, information technology (IT) plays a key role either as a central support tool or as an outcome.
\end{abstract}

\section{Introduction}

Climate and environmental changes, constant and rapid evolution of digital technologies, population aging, dwindling resources, and financial crises are among the many unprecedented challenges faced by public sector organizations (PSOs). Not only are PSOs facing structural and conjectural pressures that limit their resources [1], but they also need to address citizens, communities as well as private organizations expectations towards an improvement of their services in terms of availability, flexibility, quality and effectiveness [2, 3]. In addition, PSOs are facing pressures to increase transparency, improve participation in governance processes and foster collaboration [4]. All of these interrelated factors create a volatile, uncertain and increasingly complex environment that requires specialized knowledge coming from a wider number of contributors [5]. New innovative and collaborative approaches are therefore needed in order to solve what are often characterized as "wicked problems" [2].

Innovation, which refers to "a micro and macro dynamic process by which agents, organizations, institutions and the macro structure of the economy are transformed by the effects of a novel idea" [6, p.123], can help PSOs to adapt to this complex and changing environment. Indeed, innovation in the public sector has been shown to contribute to the improvement of quality, effectiveness and efficiency of public services, the increase of citizen satisfaction and trust, the involvement of citizens and private partners $[1,5$, 7-10].

Most public service innovations are episodic and mainly driven by accidental events such as a response to new legislation, crises or spending cuts $[2,11]$. A number of contextual factors hinder PSOs abilities to develop sustainable innovative capacities. For instance, PSOs are usually less innovative that they should be, because public sector innovation is weakly incentivized and measuring innovation performance is difficult [6]. Furthermore, PSOs have to evolve in a complex, multifunctional, risk-averse and legal-based environment with bureaucratic rules and performance indicators which tend to prevent innovation $[2,11]$.

Therefore, in order to be innovative, PSOs need to change their organizational forms and interaction modes. Several propositions have been formulated to improve public sector innovations such as 
deregulation, privatization, recruiting recognized innovators, design and test promising ideas, or create favorable conditions where drastic ideas can evolve [2, 6]. Previous research has also advanced several strategies of openness and collaboration, such as creativity networks, crowdsourcing or user-driven innovation $[2,12-14]$. Such strategies relate broadly to the concept of open innovation (OI) that generally refers to processes that purposively integrate "inflows and out-flows of knowledge to accelerate internal innovation, and expand the markets for external use of innovation, respectively" [12, p. 1].

In practice OI is not just one approach but many different approaches, each presenting enormous opportunities as well as major challenges. Huizingh [15] argues that "open innovation requires managers to make new decisions in developing and exploiting innovation activities. When, how, with whom, with what purpose, and in what way should they cooperate with outside parties (p. 6)". Thus, in order to maximize their value and benefits, PSOs need to develop the organizational capabilities necessary for the development and sustained exploitation of OI initiatives [16]. However, the study of OI, in particular the organizational capabilities needed to implement OI in the public sector, is relatively limited.

The current paper intends to address this gap by adopting a dynamic capabilities perspective to study the organizational actions that PSOs should implement in order to successfully engage in OI initiatives. Dynamic capabilities are defined as "the ability to integrate, build, and reconfigure internal and external competencies to address rapidly-changing environments" [17, p. 517]. Among the body of organizational capabilities, dynamic capabilities offer a useful lens to help us understand how an organization can transform its strategy, its existing resource base, as well as the whole ecosystem in which it evolves [18]. Dynamic capabilities are enabled through a set of organizational actions that are working together to facilitate changes and adaptation [19].

The current paper focuses on the implementation of successful OI initiatives and tries to answer the following research question:

What organizational actions should be deployed by PSOs in order to build the necessary dynamic capabilities for successfully engage in OI initiatives?

The paper also puts a particular emphasis on the role of information technology (IT) in the deployment and execution of OI initiatives. To answer the research question, an analysis of 100 case study reports of OI initiatives in the public sector has been conducted. A total of 16 key organizational actions deployed by PSOs to implement OI initiatives have been identified.
It is through these organizational actions that PSOs' sensing, seizing and transforming capabilities are enacted [20]. Identifying such organizational actions is a first step to help scholars better understand how dynamic capabilities support successful OI initiatives and for practitioners, to provide tangible guidance to implement and exploit OI initiatives in PSOs.

The remainder of the article is structured as follows. The first section presents the theoretical lenses: OI in the public sector context and dynamic capabilities. The second section describes the methodology used to conduct the study, while the third section provides the results. The fourth section presents a discussion and is followed by a conclusion.

\section{Theoretical background}

\subsection{Open innovation processes}

Innovation can be defined as the application of a new idea that induces a change in practice with a goal of value creation $[2,21]$. The innovation process then consists in wanting to significantly improve the existing situation by transforming innovative ideas into concrete solutions that will be implemented in the organization [22]. It is a dynamic process through which agents, organizations, institutions, and structures of the economy are transformed by the effects of new ideas [6]. In order to foster innovation in organizations, it is important to understand how to promote, support and manage each step of the innovation process. Therefore, to stimulate and sustain innovation, organizations should carry out a set of organizational actions that are usually enacted through the deployment and usage of a combination of organizational, financial, and technological resources and infrastructures [23-25]. The implementation of more efficient innovation processes is favored by new forms of interaction and organizations based on openness and collaboration [26]. In this regard, the development of OI approaches has been proposed to improve the speed of the innovation cycle, to capture collective intelligence as well as to diversify the sources of innovation, expertise and knowledge [2730].

OI is defined as the integration and voluntary dissemination of knowledge to respectively accelerate internal innovation, and foster the external use of innovation outputs [28]. While OI has many advantages, the approach also raises several questions, such as how to protect intellectual property, how to manage multiple relationships and partnerships, especially where these are spread across diverse areas of collaborations that usually involve university 
research groups, small companies and individual inventors.

Extant research suggests that the key to OI initiatives is to think carefully about what to open, when to open, how to open, with whom to open, and how to manage openness [15, 31]. As for more traditional innovation processes, OI requires the organizations and managers to undertake a set of appropriate actions to promote innovation. However, the deployment of opened and collaborative strategies to innovation is particularly complex, as it not only necessitates the successful activation of internal processes, but also requires the establishment of singular organizational structures and systems that encourage the involvement of external contributors throughout the innovation process [32].

Thus, adequate resources should be deployed in order to enable the collection of requisite knowledge at each phase of the innovation process, then supporting the identification of problems, the provision of circular feedback, the development of solutions, and the design of appropriate implementation plans [32].

\subsection{Open innovation in the public sector}

Besides the prospect of better innovation outputs and the creation of public value, motivations for implementing OI in the public sector also encompass improved transparency and accountability of institutions, enhanced political decision-making, as well as increased citizen well-being [33]. OI approaches could help PSOs extend their boundaries in order to capture and integrate external knowledge and perspectives from contributors who are traditionally not involved in innovation processes. Potential contributors include a variety of stakeholders, such as citizens, end-users, community groups, other public organizations, or private companies [34]. The plurality of potential contributors and strategies to capture external knowledge, ideas, and creativity requires PSOs to make complex but informed choices. In particular, PSOs must select appropriate approaches "along a continuum that moves from general crowdsourcing and to taskspecific peer production, with a (currently not realized) potential for future collaborative implementation of the innovations [4, p. 601]". Each approach has not only its benefits and opportunities, but also its own challenges that imply the deployment of specific resources and infrastructures. For instance, the approach of crowdsourcing involves a large and anonymous group of people, usually citizens in the public sector context, which contributes to the creation of a public good by providing answers to an open call for contribution $[4,10]$. In comparison, coproduction mode provides a more integrated and closely collaborative form of OI, where citizens and public servants cooperate in administrative and policymaking processes for the generation and delivery of public value [10]. To this end, PSOs could use the ideas and knowledge of contributors through coproduction activities facilitated, for instance, by innovation competitions such as hackathons, cooperathon or startup weekends. PSOs could also foster the self-provision of services by citizens through the installation of appropriate infrastructures, such as community portals for collaborative decision-making [10] and through effective incentives [35].

Several factors have been identified as facilitating the implementation of OI in the public sector. At the organizational level, De Vries et al. [1] have identified slack resources and notably IT investments, leadership styles, degree of risk aversion, as well as incentives and rewards, as important organizational antecedents of public sector innovations. At the individual level, employee and citizen empowerment, job-related knowledge and skill and creativity, have been suggested as main antecedents of innovativeness [1]. IT investments also play a particular and important role in OI initiatives and citizen participation [11]. Driven by the convergence of information, communication and social networking technologies, PSOs can access large and diverse knowledge bases to help them define and solve problems more efficiently. In turn, when citizens are empowered through universal and digital access to information and services, they can not only contribute more effectively to the public arena, but also enforce transparency and accountability that would result in an increased confidence in public institutions [33].

\subsection{Dynamic capabilities framework for open innovation}

The concept of dynamic capabilities, introduced by Teece et al. [17], was originally based on the resourcebased view perspective (RBV) [36, 37], and provides a more dynamic orientation for organizational capabilities [18]. Dynamic capabilities refer to "the firm's ability to integrate, build, and reconfigure internal and external competences to address rapidly changing environments" [17, p. 516]. However, as mentioned by Helfat \& Martin [38], dynamic capabilities are context specific and developing them has to be done over time and requires funds and efforts.

As suggested by Teece [20], "dynamic capabilities can be disaggregated into the capacity (1) to sense and 
shape opportunities and threats, (2) to seize opportunities, and (3) to maintain competitiveness through enhancing, combining, protecting, and, when necessary, reconfiguring the business enterprise's intangible and tangible assets (p. 1319)." To develop its ability to sense opportunities and threats, organizations have to develop a comprehensive understanding of their environment by constantly scanning, searching, and exploring across technologies and markets, i.e. sensing [20]. Then, once a new idea is sensed, organizations have to make strategic choices and invest time, efforts and funds to address the opportunity, i.e. seizing [20]. However, seizing an opportunity also means that organizations have to develop their abilities to reconfigure their assets, resources and structure, i.e. transforming/reconfiguring [20].

These three capabilities pose specific challenges to PSOs implementing OI initiatives. For instance, a strong emphasis on citizen-sourcing approaches has often provided a large amount of contributions (sensing), but no easy ways to sift through them and choose the most noteworthy one (seizing). Also, most PSOs have invested time and resources to involve external contributors to generate ideas but very limited energy in selecting, implementing and diffusing innovations (seizing and transforming) [12].

\section{Methodology}

This research project focuses on identifying organizational actions deployed by PSOs to facilitate OI processes as well as how IT can be used to support such initiatives.

In order to reach the paper's objectives, a set of OI cases in the public sector was reviewed. A total of 100 case studies of OI projects in PSOs (see Table 1 for descriptive data), launched between 2009 and 2019, have been identified and selected from the Observatory of Public Sector Innovations (OPSI) (https://oecd-opsi.org/innovation/case-studies/). The OPSI is an initiative that collects and categorizes exemplary OI projects to build an extensive database of cases from more than 60 countries. The cases are published and available on a digital platform. The objectives of the OPSI are to encourage public sector innovation by facilitating knowledge sharing. In each case, a particular emphasis was placed on sharing the challenges encountered, the key decisions made, the actions taken, and the lessons learned. To be included, a case study should have deployed an OI approach, namely, the case study must have involved at least one public sector agency with at least one stakeholder external to the focal agency (e.g. citizen, community groups, private organization, other governmental agencies, etc.).

Table 1. OI Projects Descriptive

\begin{tabular}{|c|l|c|}
\hline Dimensions & \multicolumn{1}{|c|}{ Details } & $\begin{array}{c}\text { Number } \\
\text { of cases }\end{array}$ \\
\hline \multirow{4}{*}{$\begin{array}{c}\text { Innovation } \\
\text { type }\end{array}$} & Communication innovation & 8 \\
\cline { 2 - 3 } & Organizational Innovation & 25 \\
\cline { 2 - 3 } & Process Innovation & 16 \\
\cline { 2 - 3 } & Product Innovation & 51 \\
\hline \multirow{3}{*}{$\begin{array}{c}\text { Partners } \\
\text { involved }\end{array}$} & PSO & 100 \\
\cline { 2 - 3 } & Private org & 61 \\
\cline { 2 - 3 } & Citizens & 40 \\
\cline { 2 - 3 } & Researchers & 11 \\
\hline
\end{tabular}

As a first step, organizational actions [19] used to address different challenges during OI projects, were coded using NVivo software for each of the 100 cases. Next, similar organizational actions were grouped and labels were created for each of them. To ensure reliability of the research, one author and one research assistant independently coded the 100 reports and discussed their results until a consensus view was reached. Finally, the resulting organizational actions were associated with their intended objective to facilitate either sensing, seizing, or transforming dynamic capabilities.

\section{Results}

A total of 16 organizational actions deployed by PSOs to implement successful OI initiatives have been identified. It is through these organizational actions that PSOs' dynamic capabilities of sensing, seizing and transforming were enacted and collectively used to achieve OI initiatives. As shown in Table 2, each organizational action can potentially reflect more than one type of dynamic capability.

\subsection{Dynamic capability of sensing opportunities or threats}

In order to sense new opportunities or threats, organizational actions used by PSOs when implementing OI initiatives are oriented towards strengthening relationships between their various partners. Opportunities to meet, whether online or in person, are created to foster interactions between 
individuals and organizations. Online, PSO can use dedicated OI platforms to facilitate ideas generation and knowledge sharing between partners (see OA\#1 in Table 2), and/or build an online presence on existing social media (e.g. Twitter, Facebook) (OA\#2).

On these platforms, users, be they existing partners or external stakeholders, can submit ideas that will then be discussed and/or voted on by participants. Moreover, social media is not only use to transmit relevant information to the public or to collect ideas, but also to identify new individuals and/or organizations who can participate or get involve in the innovation effort. PSOs can also organize in-person meeting events, such as hackathon, rallies, cooperathon, or workshops to transmit information related to innovation objectives, in order to generate interests in the innovation and to promote the development of new ideas (OA\#3).

The results also showed that a good understanding of potential users (e.g. citizens), notably in terms of knowledge, expertise and/or interests, helps to identify innovation opportunities that could meet their needs (OA\#4). This can be done by working with partners who work directly with users. Observations, surveys, face-to-face or online communication, or even ethnography can also be used to better understand potential users. The generation of ideas is not only done through external actors but can also come from the organization itself or from the ecosystem in which it operates. Thus, developing an organizational culture that values experimentation and experiential learning facilitates these processes and has been highlighted in several cases (OA\#15).

\subsection{Dynamic capability of seizing opportunities}

In order to seize opportunities among different innovative avenues, PSO can put in place different organizational actions. Our results revealed 7 distinct organizational actions that are intended at seizing innovation opportunities (OA\#2-6 and OA\#15-16). A good understanding of potential users, in terms of knowledge, capabilities and interests, enables PSOs to seize the opportunities that better fit their needs (OA\#3). Meetings between OI partners and external stakeholders are also important occasions to receive feedback in order to select the most appropriate technology or service to develop (OA\#2, OA\#4).

In terms of processes, the adoption of agile methods (OA\#6) and the development of pilots and pre-tests throughout the innovation process (OA\#5) are two other organizational actions that can help PSO to better seize opportunities. Agile practices, as well as other forms of iterative development, provide organizations the ability to receive continuous feedback and to adapt quickly to changes.

\subsection{Dynamic capability of transforming the organization}

The dynamic capability of transforming the organization is reflected in 11 organizational actions (OA\#6-16). First, OI approaches involve the integration of external knowledge and perspectives from a plurality of contributors, including stakeholders that are not traditionally involved in innovation processes (e.g. citizens). Therefore, identifying and selecting the right partners appears to be a very important organizational action (OA\#11). In order to build multidisciplinary innovation teams, it is deemed important to select partners that can add different knowledge, skills, but also believe in the project. In addition, partners who understand users' needs (e.g. citizens) or those who have access to the users or are close to them can also be beneficial for the innovation process.

Second, effective collaboration is essential to successfully carry out an innovation process in an OI context. To facilitate collaboration, the use of a collaborative framework that defines the roles of each partners as well as the communication protocols and tools is considered important (OA\#12). This type of framework aims to ease communication between partners and enables everyone to be informed in a transparent way despite the difficulties related to different perspectives, organizational background, barriers or knowledge and skills. A complementary organizational action is to coordinate partners' efforts using a collaborative platform (OA\#16). The use of such digital platforms strengthens partners' commitment by sharing project progress, facilitating communication, information exchange, and collaboration between project stakeholders. Finally, monitoring innovation processes and sharing project progress also facilitate collaboration by ensuring that each partner knows who should do what (OA\#13). This is achieved by using a well-defined governance framework, in which the roles and responsibilities of each are clearly described. The results also revealed that PSOs should be cautious about allocating sufficient financial resources throughout the different phases of the project (OA\#8).

Third, on the management side, obtaining political and senior level support and developing strong leadership are also two important organizational actions that helps PSOs to transform themselves (OA\#9-10). In addition, the related organizational action of enhancing partners' motivation and 
commitment to participate in the project is another way to facilitate organizational transformation (OA\#7). Enhanced motivation and commitment can be achieved by building trust in the process, promoting the benefits of the innovation, and clarifying each partners' gain (recognition, monetary rewards, etc.).

Transforming the organization also involves organizational culture. Several cases mentioned nurturing an open and innovation culture as an important organizational action to realize (OA\#15). Ideally, an organizational culture in which experimentation and experiential learning are encouraged as well as patience, supportive and accept risk, should be promoted. Indeed, open communication and transparency enable people to feel free to report issues and failures. People should also be willing to follow and execute ideas that are coming from outside the organization.

Finally, building a flexible IT infrastructure that can be easily expanded to support the evolution of innovation is another important aspect of organizational transformation (OA\#14). In several cases in our sample, the use of open source, open code, and, when possible, open data approaches with publicly available data repositories, was promoted to ease the innovation development by different partners.

Table 2. Organizational Actions Deployed by PSO to Implement OI initiatives

\begin{tabular}{|c|c|c|c|c|c|c|}
\hline \multicolumn{3}{|r|}{ Organizational actions (OA) } & \multicolumn{3}{|c|}{$\begin{array}{c}\text { Enabled } \\
\text { dynamic } \\
\text { capabilities }\end{array}$} & \multirow[t]{2}{*}{$\begin{array}{c}\text { Case } \\
\text { ID }\end{array}$} \\
\hline$\#$ & Label & Description & Sense & Seize & Tran. & \\
\hline 1 & $\begin{array}{l}\text { Generate and collect } \\
\text { ideas using a digital } \\
\text { platform }\end{array}$ & $\begin{array}{l}\text { Build a digital platform to enable end-users, citizens and } \\
\text { stakeholders to generate new ideas and to allow feedback loops } \\
\text { for the innovation outcomes that are being developed. This } \\
\text { platform should also promote interactions between its members } \\
\text { (citizens, project stakeholders, etc.) to foster idea generation. }\end{array}$ & $\mathbf{X}$ & & & $\begin{array}{l}1 ; 29 ; 35 ; 60 ; \\
61 ; 79 ; 83 ; 90\end{array}$ \\
\hline 2 & $\begin{array}{l}\text { Build a social media } \\
\text { presence }\end{array}$ & $\begin{array}{l}\text { Build a social media presence to foster interactions between } \\
\text { people both inside and outside the organization (citizens, other } \\
\text { partners, etc.). To do so, organizations should identify the target } \\
\text { audience and the most efficient channel(s) to reach it (Facebook, } \\
\text { Twitter, etc.). Social media presence allows organizations to } \\
\text { identify new people who can assist the innovation effort. }\end{array}$ & $\mathbf{X}$ & $\mathbf{X}$ & & $\begin{array}{l}14 ; 15 ; 22 ; 29 \\
81 ; 90\end{array}$ \\
\hline 3 & $\begin{array}{l}\text { Organize meetings } \\
\text { between OI partners }\end{array}$ & $\begin{array}{l}\text { Organize opportunities for meetings, such as hackathons, } \\
\text { cooperathon, rallies, workshops or other contests. These } \\
\text { opportunities can be used to transmit feedback on the innovation } \\
\text { process, to generate interest in the innovation, and to reach new } \\
\text { potential partners and foster interactions between them. }\end{array}$ & $\mathbf{X}$ & $\mathbf{X}$ & & $\begin{array}{l}1 ; 35 ; 57 ; 60 ; \\
63 ; 77 ; 79 ; 86 ; \\
91\end{array}$ \\
\hline 4 & $\begin{array}{l}\text { Map end users' } \\
\text { needs and } \\
\text { capabilities }\end{array}$ & $\begin{array}{l}\text { Map potential users of the innovation outcomes in terms of } \\
\text { knowledge, capabilities (e.g. technical skills; computer literacy), } \\
\text { interests and preferences. It can be done by working with partners } \\
\text { who work directly with users. Observations, surveys, face-to-face } \\
\text { or online communication can be used to understand users' needs. } \\
\text { The objective is to develop an innovation that fit their needs, and } \\
\text { to promote innovation adoption. }\end{array}$ & $\mathbf{X}$ & $\mathbf{X}$ & & $\begin{array}{l}1 ; 12 ; 14 ; 16 ; \\
20 ; 39 ; 55 ; 56 ; \\
60 ; 61 ; 62 ; 64 ; \\
65 ; 72 ; 77 ; 79 ; \\
80 ; 81 ; 83 ; 85 \\
90 ; 98\end{array}$ \\
\hline 5 & $\begin{array}{l}\text { Develop pilots and } \\
\text { pretests }\end{array}$ & $\begin{array}{l}\text { Develop pilots and carry out multiple tests of the innovation } \\
\text { outcomes. This could be done ideally with real users at different } \\
\text { stages of the project in order to get feedback quickly and be able } \\
\text { to adjust accordingly. Pilots and tests can help to select the } \\
\text { appropriate technologies and features to meet end users' needs. }\end{array}$ & & $\mathbf{X}$ & & $\begin{array}{l}11 ; 13 ; 17 ; 19 ; \\
20 ; 24 ; 51 ; 55 ; \\
59 ; 76 ; 81\end{array}$ \\
\hline 6 & $\begin{array}{l}\text { Adopt agile } \\
\text { methodologies }\end{array}$ & $\begin{array}{l}\text { Adopt agile and iterative development methods, to have the } \\
\text { ability to improve continuously, to deliver more frequently and } \\
\text { quickly (to improve time-to-market ratio), to adapt quickly to } \\
\text { changes, to have a better understanding of user needs and to } \\
\text { constantly readjust to technological developments. }\end{array}$ & & $\mathbf{X}$ & $\mathbf{X}$ & $\begin{array}{l}2 ; 10 ; 11 ; 51 ; \\
53 ; 55 ; 63 ; 64 ; \\
65 ; 75 ; 82 ; 97\end{array}$ \\
\hline
\end{tabular}




\begin{tabular}{|c|c|c|c|c|c|c|}
\hline 7 & $\begin{array}{l}\text { Enhance partners' } \\
\text { motivation and } \\
\text { commitment }\end{array}$ & $\begin{array}{l}\text { Enhance project stakeholders' motivation and commitment to } \\
\text { participate in the project, bring and try new ideas. It can be } \\
\text { achieved by facilitating collaboration, building trust, and } \\
\text { empowering partners. }\end{array}$ & & & $\mathbf{X}$ & $\begin{array}{l}5 ; 7 ; 8 ; 15 ; \\
16 ; 19 ; 51 ; 54 ; \\
60 ; 61 ; 62 ; 65 ; \\
67 ; 70 ; 74 ; 75 ; \\
82 ; 83 ; 86 ; 87 ; \\
88 ; 90 ; 91 ; 98\end{array}$ \\
\hline 8 & $\begin{array}{l}\text { Allocate sufficient } \\
\text { financial resources } \\
\text { to the projects }\end{array}$ & $\begin{array}{l}\text { Ensure that financial resources are sufficient throughout the } \\
\text { different phases of the projects in order to enable continuous } \\
\text { development. }\end{array}$ & & & $\mathbf{X}$ & $\begin{array}{l}2 ; 3 ; 4 ; 8 ; 26 . ; \\
71 ; 76 ; 84\end{array}$ \\
\hline 9 & $\begin{array}{l}\text { Gain political and } \\
\text { senior level support }\end{array}$ & $\begin{array}{l}\text { Gain political and senior level support during all stages of the } \\
\text { innovation process, across governments, agencies and } \\
\text { collaborative partners, in order to enhance stakeholder's } \\
\text { engagement and build momentum in the project. }\end{array}$ & & & $\mathbf{X}$ & $\begin{array}{l}2 ; 3 ; 5 ; 10 ; \\
12 ; 17 ; 19 ; 21 ; \\
27 ; 51 ; 54 ; 57 \\
58 ; 60 ; 68 ; 76 \\
82 ; 90 ; 91\end{array}$ \\
\hline 10 & $\begin{array}{l}\text { Develop strong } \\
\text { leadership and } \\
\text { vision }\end{array}$ & $\begin{array}{l}\text { Develop a strong and consistent leadership in the innovation } \\
\text { project. A clear vision of the innovation process and well-defined } \\
\text { project objectives, enable leaders to motivate people, to influence } \\
\text { stakeholder's engagement. }\end{array}$ & & & $\mathbf{X}$ & $\begin{array}{l}2 ; 3 ; 15 ; 26 ; \\
51 ; 52 ; 60 ; 63 ; \\
68 ; 73 ; 74 ; 75 ; \\
87 ; 97\end{array}$ \\
\hline 11 & $\begin{array}{l}\text { Identify and select } \\
\text { the right partners }\end{array}$ & $\begin{array}{l}\text { Define the criteria to take part of the innovation process, to build } \\
\text { multidisciplinary teams. Select partners that can add different } \\
\text { knowledge, skills and believe in the project. Find partners who } \\
\text { technical skills, but also who understand users' needs (e.g. } \\
\text { citizens) and who have access or who are close to them }\end{array}$ & & & $\mathbf{X}$ & $\begin{array}{l}2 ; 4 ; 7 ; 23 ; \\
25 ; 27 ; 49 ; 57 ; \\
60 ; 62 ; 63 ; 64 ; \\
65 ; 67 ; 75 ; 81\end{array}$ \\
\hline 12 & $\begin{array}{l}\text { Use a structured } \\
\text { collaborative } \\
\text { framework }\end{array}$ & $\begin{array}{l}\text { Use a collaborative framework that defines a shared } \\
\text { methodology, the roles of each partners and the communication } \\
\text { protocols and tools so that their engagement in the project is well } \\
\text { structured. The goal is constant communication between partners } \\
\text { and that everyone is informed in a transparent way. } \\
\text { Partners should also be consulted adequately in order to receive } \\
\text { continuous feedback on the innovation development. }\end{array}$ & & & $\mathbf{X}$ & $\begin{array}{l}3 ; 4 ; 6 ; 7 ; 8 ; \\
13 ; 20 ; 23 ; 57 ; \\
58 ; 63 ; 64 ; 65 ; \\
72 ; 74 ; 84 ; 85 \\
86 ; 98\end{array}$ \\
\hline 13 & $\begin{array}{l}\text { Monitor innovation } \\
\text { processes }\end{array}$ & $\begin{array}{l}\text { Constantly monitor the innovation projects to ensure partners' } \\
\text { engagement and innovation development. This is achieved by } \\
\text { using a well-defined governance framework, in which the roles } \\
\text { and responsibilities of each are defined. The fact that each partner } \\
\text { knows who should do what ensures an efficient flow between } \\
\text { them and facilitate collaboration. Constant monitoring also } \\
\text { makes it possible to learn, adjust processes as needed and track } \\
\text { new opportunities. }\end{array}$ & & & $\mathbf{X}$ & $\begin{array}{l}4 ; 8 ; 13 ; 15 ; \\
63 ; 64 ; 65 ; 68 ; \\
69 ; 73 ; 86 ; 88 \\
90 ; 95 ; 97\end{array}$ \\
\hline 14 & $\begin{array}{l}\text { Build a flexible and } \\
\text { open IT } \\
\text { infrastructure }\end{array}$ & $\begin{array}{l}\text { Build a flexible IT infrastructure that can be easily expanded to } \\
\text { support the evolution of innovation. Promote the use of open } \\
\text { source and open code, and when possible, foster an open data } \\
\text { approach with publicly available data repositories to give the } \\
\text { possibility of developing the innovation by different partners. }\end{array}$ & & & $\mathbf{X}$ & $\begin{array}{l}2 ; 4 ; 10 ; 45 ; \\
49 ; 52 ; 55 ; 58 \\
74 ; 81\end{array}$ \\
\hline 15 & $\begin{array}{l}\text { Nurture an open and } \\
\text { innovative culture }\end{array}$ & $\begin{array}{l}\text { Foster an organizational culture where experimentation and } \\
\text { experiential learning is encouraged. An environment where } \\
\text { patience, support and risk-taking are cultivated. Open } \\
\text { communication and transparency are essential, so employees feel } \\
\text { free to report issues and also be willing to follow and execute } \\
\text { ideas that are coming from outside of the organization. }\end{array}$ & $\mathbf{X}$ & $\mathbf{X}$ & $\mathbf{X}$ & $\begin{array}{l}2 ; 6 ; 15 ; 20 ; \\
27 ; 51 ; 52 ; 54 ; \\
56 ; 57 ; 60 ; 64 ; \\
65 ; 75 ; 90\end{array}$ \\
\hline 16 & $\begin{array}{l}\text { Coordinate partners' } \\
\text { efforts using } \\
\text { collaborative } \\
\text { platforms }\end{array}$ & $\begin{array}{l}\text { Use OI platforms to coordinate partners' efforts in the } \\
\text { development process. Internal and external stakeholders should } \\
\text { be allowed to participate in open collaboration. These platforms } \\
\text { should foster partners commitment by sharing project progress, } \\
\text { facilitating communication, information exchange, generation } \\
\text { and selection of ideas, and collaboration between project } \\
\text { stakeholders that have different knowledge / skills and } \\
\text { organizational backgrounds. }\end{array}$ & $\mathbf{X}$ & $\mathbf{X}$ & $\mathbf{X}$ & $\begin{array}{l}8 ; 23 ; 27 ; 29 ; \\
39 ; 50 ; 54 ; 63 ; \\
65 ; 91\end{array}$ \\
\hline
\end{tabular}




\section{Discussion}

Through an analysis of 100 exemplary OI case studies, we identified organizational actions through which PSOs' sensing, seizing and transforming capabilities [20] are enacted to engage in OI initiatives. These organizational actions were deployed to deal with the challenges and the opportunities of OI initiatives.

A small proportion of the organizational actions identified (6 out of 16) were associated with the sensing capability. These actions (i.e., generating and collecting ideas (OA\#1), building a social media presence $(\mathrm{OA \# 2})$, organizing meetings with OI partners (OA\#3), mapping users' needs (OA\#4), nurturing innovation culture (OA\#15) and coordinating OI partners' efforts (OA\#16) are essential in helping PSOs to develop a more comprehensive understanding of their environment as well as the OI ecosystem. In most of these organizational actions (5 out of 6), IT plays a central role as it supports the collection of data, information and/or knowledge (OA\#1), serves to communicate and diffuse data, information and/or knowledge (OA\#2), fosters collaboration (OA\#3) and coordination (OA\#16) between OI partners and helps improve the needs-innovation fit (OA\#4).

The organizational actions identified that were associated with the seizing capability represent 7 out of the 16 actions in the sample. Organizational actions, such as the development of pilots (OA\#5) or the adoption of agile approaches (OA\#6), should help PSOs make appropriate strategic choices regarding the selection, implementation and eventually diffusion of innovations. Here IT plays a central role not only in a support role, but also in an outcome role. For instance, digital platforms or online collaboration tools can support the organization in meetings coordination (OA\#3), as well as in coordination between OI partners' efforts (OA\#16). Further, while IT tools can support activities during the development of a pilot (OA\#5), in some cases, IT was also the innovation in itself, and therefore considered as an outcome of the innovative activities.

A large proportion of the organizational actions identified (11 out of 16) were associated with the transforming capability. Unlike the two previous capabilities where IT played central and supportive roles, IT seems to have a more peripheral and indirect influence with respect to enhancing partners' commitment (OA\#7), allocating financial resources (OA\#8), gaining support (OA\#9), developing strong leadership and vision (OA\#10) or using well-defined collaborative framework (OA\#12). However, some actions associated with the transforming capability seemed to rely more extensively on IT tools and platforms, notably when it comes to identifying and selecting partners (OA\#11), monitoring innovation processes (OA\#13) or coordinating OI partners (OA\#16).

Thus, when looking at organizational actions by which PSOs implement OI initiatives, our data suggests that IT has a pervasive role as it supports most of the actions deployed by the organization. In particular, our data suggest that IT was used to: 1) support the processing and sharing of information; 2) facilitate the acquisition, interpretation, assimilation, transformation, and utilization of knowledge; 3) help manage resources and tasks; 4) synchronize activities; 5) enhance communication; and 6) enable real-time information and knowledge flows [39]. However, in order to effectively use these technologies, one aspect that PSOs must not neglect is to have the appropriate IT leveraging competence in OI or the ability of the OI work units to effectively use IT functionalities to support IT-enabled OI activities [40].

\section{Conclusion}

Public sector organizations (PSOs) are facing important structural, financial, environmental and technological pressures. To adapt and respond to this complex and changing environment, PSOs need to deploy new innovative and collaborative approaches that capture and capitalize on specialized knowledge coming from a wider number of contributors. Adopting a dynamic capabilities perspective and based on an analysis of 100 case study reports of OI initiatives, 16 key organizational actions deployed by PSOs to implement OI initiatives have been identified. These 16 organizational actions enabled PSOs to enact dynamic capabilities and were collectively used to successfully engage in OI initiatives. Our data analysis also show that in most of those organizational actions, IT plays a key role as a central support tool.

One interesting future research avenue would be to look at the relationship between IT leveraging competences in OI and the dynamic capabilities deployed by PSOs to achieve OI initiatives. PSOs should take into consideration that the implementation of the identified organizational actions (Table 2) will help them develop their dynamic capabilities that would eventually help them to successful engage in OI initiatives.

Developing dynamic capabilities is an ongoing process and effort and once developed and sustained, these capabilities can be used to leverage in 
subsequent OI projects. This iterative loop will then assist PSOs to shape their organizational agility [41].

The main limitation of our research paper is that the dataset contains case studies of OI projects already completed or in progress. Therefore, some details, for instance related to the organizational actions undertaken by PSO to sense new opportunities, might be lacking.

We hope that this study's results will guide and support practitioners in engaging in and deploying OI initiatives, as well as assist scholars in their exploration of issues related to $\mathrm{OI}$ initiatives in the public sector.

\section{References}

[1] H. De Vries, V. Bekkers, and L. Tummers, "Innovation in the public sector: A systematic review and future research agenda," Public Administration, 2015.

[2] E. Sørensen and J. Torfing, "Enhancing collaborative innovation in the public sector," Administration \& Society, vol. 43, no. 8, pp. 842-868, 2011.

[3] E. Vigoda-Gadot, A. Shoham, N. Schwabsky, and A. Ruvio, "Public Sector Innovation for Europe: A Multinational Eight-Country Exploration of Citizen's Perspectives," Public Administration, vol. 86, no. 2, pp. 307-329, 2008.

[4] I. Mergel, "Opening government: Designing open innovation processes to collaborate with external problem solvers," Social Science Computer Review, vol. 33, no. 5, pp. 599612, 2015.

[5] J. F. M. Koppenjan and E.-H. Klijn, Managing uncertainties in networks: a network approach to problem solving and decision making. Psychology Press, 2004.

[6] J. Potts and T. Kastelle, "Public sector innovation research: What's next?," Innovation, vol. 12, no. 2, pp. 122-137, 2010.

[7] R. Green, G. Roos, R. Agarwal, and D. ScottKemmis, "Shaping the future through cocreation," Institute of Public Administration Australia, 2013. Retrieved on June 2019 from http://cdn.nsw.ipaa.org.au/docs/IPAANational/IPAA\%20Report_Sharing\%20the $\% 20$ Future $\% 20$ Through $\% 20$ CoCreation\%20Final.pdf

[8] F. Damanpour and M. Schneider, "Characteristics of innovation and innovation adoption in public organizations: Assessing the role of managers," Journal of Public
Administration Research and Theory, vol. 19, no. 3, pp. 495-522, 2009.

[9] V. Bekkers, J. Edelenbos, and B. Steijn, Innovation in the Public Sector: Linking Capacity and Leadership. New York, NY: Palgrave Macmillan, 2011, p. 252.

[10] D. Linders, "From e-government to wegovernment: Defining a typology for citizen coproduction in the age of social media," Government Information Quarterly, vol. 29, no. 4, pp. 446-454, 2012.

[11] S. Borins, "Encouraging innovation in the public sector," Journal of Intellectual Capital, vol. 2, no. 3, pp. 310-319, 2001.

[12] W. D. Eggers and S. K. Singh, The Public Innovator's Playbook: Nurturing bold ideas in Government. Ash Institute, Harvard Kennedy School, 2009.

[13] J. Hartley, E. Sørensen, and J. Torfing, "Collaborative innovation: A viable alternative to market competition and organizational entrepreneurship," Public Administration Review, vol. 73, no. 6, pp. 821-830, 2013.

[14] M. Stewart-Weeks and T. Kastelle, "Innovation in the public sector," Australian Journal of Public Administration, vol. 74, no. 1, pp. 63-72, 2015.

[15] E. K. Huizingh, "Open innovation: State of the art and future perspectives," Technovation, vol. 31, no. 1, pp. 2-9, 2011.

[16] C. C. Cheng and E. K. Huizingh, "Identifying Open Innovation Capabilities: A Critical Literature Review," in ISPIM Conference Proceedings, 2015, p. 1: The International Society for Professional Innovation Management (ISPIM).

[17] D. J. Teece, G. Pisano, and A. Shuen, "Dynamic Capabilities and Strategic Management," Strategic Management Journal, vol. 18, no. 7, pp. 509-509, 1997.

[18] O. Schilke, S. Hu, and C. E. Helfat, "Quo vadis, dynamic capabilities? A contentanalytic review of the current state of knowledge and recommendations for future research," Academy of Management Annals, vol. 12, no. 1, pp. 390-439, 2018.

[19] A. Yeow, C. Soh, and R. Hansen, "Aligning with new digital strategy: A dynamic capabilities approach," The Journal of Strategic Information Systems, vol. 27, no. 1, pp. 43-58, 2018.

[20] D. J. Teece, "Explicating dynamic capabilities: the nature and microfoundations of (sustainable) enterprise performance," 
Strategic Management Journal, vol. 28, no. 13, pp. 1319-1350, 2007.

[21] J. Hartley, "Innovation in governance and public services: Past and present," Public Money and Management, vol. 25, no. 1, pp. 27-34, 2005.

[22] M. T. Hansen and J. Birkinshaw, "The innovation value chain," Harvard Business Review, vol. 85, no. 6, p. 121, 2007.

[23] N. Tanaka, M. Glaude, and F. Gault, Oslo Manual - Guidelines for Collecting and Interpreting Innovation Data (The Measurement of Scientific and Technological Activities). Paris, France: OECD Publishing, 2005, p. 163.

[24] R. F. Lusch and S. Nambisan, "Service Innovation: A Service-Dominant Logic Perspective," MIS Quarterly, vol. 39, no. 1, pp. 155-175, 2015.

[25] M. Barrett, E. Davidson, J. Prabhu, and S. L. Vargo, "Service innovation in the digital age: key contributions and future directions," MIS Quarterly, vol. 39, no. 1, pp. 135-154, 2015.

[26] H. Chesbrough, "Open Innovation: A New Paradigm for Understanding Industrial Innovation," in OpenInnovation: Researching a New Paradigm, H. Chesbrough, W. Vanhaverbeke, and J. West, Eds. Oxford: Oxford University Press, 2006, pp. 1-12.

[27] C. Bason, Leading public sector innovation: Co-creating for a better society. Great Britain: Policy Press, 2010, p. 288.

[28] H. Chesbrough and M. Bogers, "Explicating Open Innovation: Clarifying an Emerging Paradigm for Understanding Innovation," in Open Innovation: New Frontiers and Applications, H. Chesbrough, W. Vanhaverbeke, and J. West, Eds. Oxford: Oxford University Press, 2014, pp. 3-28.

[29] A. Kankanhalli, A. Zuiderwijk, and G. K. Tayi, "Open innovation in the public sector: A research agenda," Government Information Quarterly, vol. 34, no. 1, pp. 8489, 2017.

[30] J. West and M. Bogers, "Open innovation: current status and research opportunities," Innovation, vol. 19, no. 1, pp. 43-50, 2017.

[31] A. King and K. R. Lakhani, "Using open innovation to identify the best ideas," MIT Sloan Management Review, vol. 55, no. 1, p. 41, 2013.

[32] T. C. M. Martins, P. H. de Souza Bermejo, and W. V. B. de Souza, "Open Innovation for Citizen Coproduction," in International
Conference on Electronic Government and the Information Systems Perspective, 2015, pp. 177-188: Springer.

[33] D. Hilgers and C. Ihl, "Citizensourcing: Applying the concept of open innovation to the public sector," The International Journal of Public Participation, vol. 4, no. 1, pp. 6788, 2010.

[34] B. Bommert, "Collaborative innovation in the public sector. ," International Public Management Review, vol. 11, no. 1, pp. 1553, 2010.

[35] J. Corbett, M. Templier, and H. Takeda, "The Making of a 'Top' Open Data City: A Case Study of Edmonton's Open Data Initiative," in Proceedings of the 51st Hawaii International Conference on System Sciences, 2018.

[36] B. Wernerfelt, "A resource-based view of the firm," Strategic Management Journal, vol. 5, no. 2, pp. 171-180, 1984.

[37] C. E. Helfat and M. A. Peteraf, "The dynamic resource-based view: Capability lifecycles," Strategic Management Journal, vol. 24, no. 10, pp. 997-1010, 2003.

[38] C. E. Helfat and J. A. Martin, "Dynamic managerial capabilities: Review and assessment of managerial impact on strategic change," Journal of Management, vol. 41, no. 5, pp. 1281-1312, 2015.

[39] P. A. Pavlou and O. A. El Sawy, "The "Third Hand": IT-Enabled Competitive Advantage in Turbulence Through Improvisational Capabilities," Information Systems Research, vol. 21, no. 3, pp. 443-443-471,656-657, 2010.

[40] P. A. Pavlou and O. A. El Sawy, "From IT Leveraging Competence to Competitive Advantage in Turbulent Environments: The Case of New Product Development," Information Systems Research, vol. 17, no. 3, pp. 198-227, 2006.

[41] V. Sambamurthy, A. Bharadwaj, and V. Grover, "Shaping agility through digital options: Reconceptualizing the role of information technology in contemporary firms," MIS Quarterly, pp. 237-263, 2003. 